\title{
Wireless Tomography, Part I: A Novel Approach to Remote Sensing
}

\author{
R. C. Qiu*, M. C. Wicks ${ }^{\dagger}$, L. Li* ${ }^{*}$ Z. Hu*, S. J. Hou*, P. Chen ${ }^{\S}$, and J. P. Browning ${ }^{\ddagger}$ \\ ${ }^{*}$ Cognitive Radio Insitute, Department of Electrical and Computer Engineering, \\ Center for Manufacturing Research, Tennessee Technological University, \\ Cookeville, Tennessee, Email: rqiu@tntech.edu \\ ${ }^{\dagger}$ Air Force Research Laboratory, Sensors Directorate, Rome, New York \\ Email: Michael.Wicks@rl.af.mil \\ $\S$ Department of Mathematics, Syracuse University, Syracuse, New York \\ ${ }_{\ddagger}^{\ddagger}$ Air Force Research Laboratory, Sensors Directorate, Radar Signal Processing Branch, Dayton, Ohio \\ Email: James. Browning.12@us.af.mil
}

\begin{abstract}
Wireless tomography, a novel approach to remote sensing, is proposed in Part $I$ of this series. The methodology, literature review, related work, and system engineering are presented. Concrete algorithms and hardware platforms are implemented to demonstrate this concept. Self-cohering tomography is studied in depth. More research will be reported, following this initiative.
\end{abstract}

Index Terms - radio frequency tomography, remote sensing, cognitive radar, cognitive radio.

\section{INTRODUCTION}

The ever increasing demand on remote sensing capabilities directly conflicts with the accelerating awareness of loss of spectrum allocation [1]. Increased spectral awareness and waveform diversity can be applied to solve this problem. The FCC recommends spectrum policy [2] that makes 500 megahertz of spectrum newly available for broadband within 10 years, of which 300 megahertz should be made available for mobile use within five years. The need for dynamic spectrum access using cognitive radio [3] is real and immediate. This paper series [4], [5] is going to bring together wireless communications with remote sensing, especially radio frequency tomography. This is Part I.

\section{A. Cognitive Radio and Cognitive Radar: A Convergence}

Future applications demand that we limit the number of radio platforms. There is a need to integrate cognitive radio and cognitive radar into one flexible radio platform [6]. This kind of convergence (for voice and data) has been the driver in the wireless industry. This trend seems to be reasonable for management of the next generation energy grid - the smart grid. Cognitive radar (remote sensing) can be used for smart grid applications as well. The idea of using cognitive radio in the smart grid seems be proposed in the literature, for the first time, in [7]-[10] $]^{1}$.

\footnotetext{
${ }^{1}$ In particular, one of the three objectives of the submitted proposal [7] in 2009 is "apply the proposed network testbed for the smart grid". The twopage white paper [11] is undated and was not brought to our attention (through Qiu's student) until June 2010.
}

\section{B. Wireless Tomography-A Novel Approach to Remote Sens-} ing

Every radio frequency (RF) signal needs spectrum access. The whole industry is around $\$ 700$ billions in the US alone. Wireless phone and Internet access consumes the lion's share. It is natural to leverage this huge investment in the wireless industry. If the huge scale of the wireless market can be used to replace Ad Hoc devices for RF tomography [12], the cost will be driven down ruthlessly by Moore's Law and Metcalf's Law. To reflect this vision, we are justified in coining a new acronym "wireless tomography", to differentiate between old and new. More precisely, we argue that only COTS communications components should be used for this purpose.

Ideally, necessary consideration for sensing needs should be made in the initial design. This is not the case, however, in the real world. Vendors want to reduce cost by avoiding multifunctional radio applications. The advent of programmable radio platforms, such as software-defined radio (SDR), makes this vision more realistic. Today's technology — using FPGA and DSP - is still too costly for this purpose. Our focus is to develop tomorrow's technology, by using today's science to design and build a prototype and demonstrate the system concept.

\section{Software-Defined Radio Based System Testbed}

A new generation of general purpose SDR, called universal software radio peripheral (USRP2) provided by Ettus Research [13], is currently available in the market. This platform meets our needs. Hardware testbed development is on-going at Tennessee Technological University (TTU). The initial results will be released in several months. Part II [5] of this series will address the key designs and algorithms.

\section{Literature Review And Related Work}

In the context of wireless tomography, it seems that only two groups, [14]-[16] and [17], have conducted research on incoherent tomography. In the following, the availability of phase information, is used for classification in the literature. 


\section{A. Incoherent Tomography}

First generation computerized tomography (CT) algorithms use attenuation only [18], [19]. ZigBee sensors (IEEE 802.15.4) are used in pairs to sense the attenuation between a pair of sensors in [14]-[16] and [17].

\section{B. Coherent Tomography}

Diffraction tomography requires both phase and signal intensity (amplitude) of the transmitted packets. Phase is not easily obtained in the ZigBee-like network the above.

Wicks and his colleagues [12], [20]-[30] used tomography for remote sensing, in particular, for tunnel detection [31], [32]. Geometric diversity obtained through multistatic radar operations is the central idea, especially for discrete ultra narrowband (UNB) frequencies. The information content (or degrees of freedom) of the temporal spatial signal is the ultimate concern. So, spatial diversity can be traded for signal bandwidth. For some special needs, such as noise radar, ultrawideband (UWB) waveforms are preferred.

A long line of research, called time reversal imaging, addresses two basic ingredients: (1) multiple input, multiple output (MIMO) - multistatic radar operations; (2) the methodology of treating sensors as part of propagation channel. Time reversal imaging is analogous to wireless tomography in the sense that MIMO lies at the heart of these two distinct frameworks. The seamless combination of sensors and radio propagation is made possible by low-cost computing and exploited by waveform diversity through the use of programmable waveform generators.

Indeed, MIMO ties together wireless tomography and time reversal imaging, and includes the latter two as special casesin a mathematical framework. The three, however, have different meanings and implementations. MIMO radar or sensing is analogous to MIMO wireless communication. MIMO radar and communications requires the phase synchronization between different waveforms on transmit and receive. Wireless tomography and time reversal imaging, on the other hand, impose no such constraint. Also, the matrix size in wireless tomography is much larger than that of traditional MIMO communication and MIMO radar.

\section{Self-Coherent Tomography-Phase Reconstruction}

If we want to use communications components only, phase information may be inaccurate or very difficult to obtain. A different approach, called self-coherent tomography, is required to acquire the phase information, through the process of phase reconstruction. Two steps [33] are needed: (1) Phase reconstruction and (2) standard coherent tomographic processing, such as time reversal imaging, are used for image formation.

An exhaustive search has been made in IEEE Xplore, using the key words "amplitude only", "intensity only", "phaseless", "phase retrieval", etc. A similar search has been made in optics but the papers are not listed here. To highlight the evolution of the central idea, all papers are sorted in chronological order in [33]-[215]. In general, papers are traced back to 1981.
Earlier comparison of algorithms is made in [34], [35]. No attempt is made herein to compare and treat these papers. We comment, however, on the key conceptual development that is relevant to our interest - the first self-coherent system using wireless tomography. We do this in chronological order.

Practical considerations in microwave diagnostics are made in [36], [39], [42]. A long line of work [77], [84], [90], [91], [99], [104], [105], [108], [110], [128], [133], [216]-[218] has led to algorithms that are practical. The algorithm, called Fourier Harmonics Method proposed in [157], [166], [169], [179], has been implemented and is reported in Section III-A.

Another algorithm, called Radiating Currents Method proposed in [206], [213], is also implemented and is reported in Section III-B. The goal is to find out if there is any practical application.

The use of multi-frequency data [139], [143], [164], [166], [187], [212] is an important idea relevant to our problem at hand. Non-contiguous-orthogonal frequency division multiplexing (NC-OFDM) offers flexible spectrum access in cognitive radio and cognitive radar: through the control of carriers power allocation. The above multi-frequency formalism is compatible with NC-OFDM. This line of thought will be explored, in depth, in the next paper of this series.

The Born approximation and Rytov approximations [18], only valid for weak scatterer assumptions, are the main stream frameworks in the literature. Metallic targets are of our interest, however, can not be treated using these frameworks. The inverse problems of metallic targets have been treated in [198], [219]-[225].

The use of phaseless tomography is reported in millimeterand sub-millimeter-wave [204], [214] and in terahertz frequencies [177], [226]. The idea of compressed sensing is connected to the phase retrieval problem in [177]. Sampling in space and time is essential in tomographic imaging: compressed sensing is essential. The low signal-to-noise-ratio (SNR) paradigm for this problem is an unsolved problem.

Experimental data that is made available, online by [168], has been used to test the algorithms in [33], [166], [193]. The TE and TM database is from 2 to $10 \mathrm{GHz}$ and even $18 \mathrm{GHz}$ for the most complex targets.

\section{Time Reversal Imaging-A Coherent Tomography Ap- proach}

Once the phase is retraced during phase reconstruction, standard coherent algorithms are applied. This two-step approach [33] facilitates the management of the non-linearity of the inverse problem.

Time reversal imaging has been chosen for several reasons: (1) Using a testbed, TTU has experimentally demonstrated (for the first time) time reversal techniques in the context of ultrawideband communications. The hardware platform ${ }^{2}$ [227], [228] can be leveraged for wireless tomography, especially in the context of noise radar that is ultra-wideband in nature. (2)

\footnotetext{
${ }^{2}$ This work has been funded in the last seven years by ARL, ARO, NSF and ONR.
} 
This technique has many advantages. For example, it can be used for both weak scatterers and metallic scatterers. It uses the active MIMO array, in which each element in the array can both transmit a waveform and record a reflected signalenabling waveform diversity. Multipath can be exploited to improve image resolution. It is valid for both point scatterers and extended targets.

An attempt has be made to list all the papers that are sorted in chronological order [143], [158], [184], [229]-[321]. We know many papers are missing in this list. It is hoped that the most significant papers have been included. Our selection of a particular scheme for implementation is based upon this list. We have taken a system engineering approach. No attempt has been made to develop new algorithms. Our top concern is to develop a first generation system that works.

The first paper is Prada and Fink [229]. The time reversal operator - a MIMO matrix or linear integral operator (continuous-time case) - has all the information about the circuitry, antenna, background medium and scatterer (target). In particular, the eigenvalue(s) of this (matrix) operator depends on the reflectivity of the target, while its eigenvector provides the phase and amplitude law to focus to the target. These eigenvectors are important for low SNR such as $-25 \mathrm{~dB}$ where only the leading eigenvectors are reliable features [10], [322]. Cognitive radio and cognitive radar [3], [6] often exhibit low SNR. The time reversal operator can be viewed as providing cooperative sensing in cognitive radar. We will demonstrate, elsewhere, that time reversal can be used in low SNR.

The second conceptual breakthrough [239], [240], [246], [263], [269], [277], [284] is to tie together, in a closed form, the target geometry and the eigenvalues/eigenvectors. The eigenvalues/eigenvectors can be calculated from the time reversal matrix that is formed, directly, from sensor measurements. Experiments are reported in [315]. The advent of cost-effective sensors and computing, especially robots as distributed sensors [28], [323] and cloud computing [324], makes this approach powerful.

The third conceptual breakthrough is to use a sub-space based approach in time reversal MIMO to develop MUSIClike algorithms. This is achieved independently by [259] and by [158], [253], [255], [265], [266], [272], [273], [292], [293], [305], [317], [319]. The key is to treat this MIMO matrix as a covariance matrix - random matrix theory (RMT) [310], [313], [314], in general. The matrix size in traditional MIMO communications and radar is small, typically two times four. The matrix size of the time reversal imaging matrix is much larger. Often, only the asymptotic limit of random matrix theory is available in a closed form. As a result, random matrix theory may be suitable for our problem at hand.

Interestingly, time reversal MUSIC is also valid for intensity only (incoherent tomography) imaging [184].

\section{Phase Reconstruction}

As mentioned before, phase reconstruction is the first step in self-coherent tomography. In wireless tomography, phase reconstruction means reconstructing the scattered field from the information in the incident field and squared amplitude of the total field. The problem considered herein differs from the standard phase reconstruction problem [128] as both the amplitude and phase information have to be reconstructed.

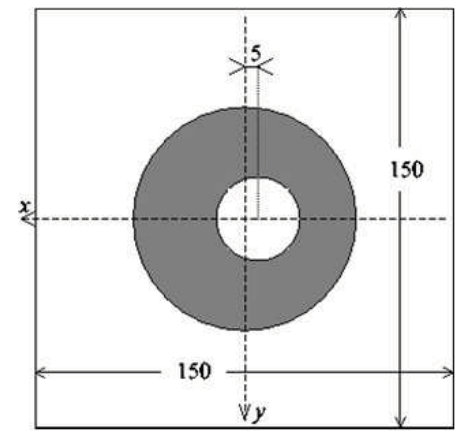

Fig. 1. Extended target.

The scenario in the problem considered, shown in Fig. 1, has the following properties: the investigated domain $\Omega$ is a circle with radius $a$ which encloses one or more targets; the incident TM wave from angle $\theta_{i}$ impinges on the investigated domain $\Omega$; the measurement domain $\Gamma$ is a circle with radius $b$; there are $L$ receivers with angle $\theta_{0}$ on the circle; $\Omega$ and $\Gamma$ are concentric; the background medium is assumed to be homogeneous with dielectric permittivity of $\varepsilon_{b}$ and magnetic permittivity of $\mu_{0}$. The scattering equations based on above assumptions are [169]

$$
\begin{aligned}
E(\mathbf{r}) & =E_{\text {inc }, i}(\mathbf{r})+k^{2} \times \int_{\Omega} G\left(\mathbf{r}-\mathbf{r}^{\prime}\right) \chi\left(\mathbf{r}^{\prime}\right) E\left(\mathbf{r}^{\prime}\right) d \mathbf{r}^{\prime} \\
& =E_{\text {inc }, i}(\mathbf{r})+A_{i}[\chi E], \mathbf{r} \in \Omega \\
E_{\text {tot }}\left(\theta_{0}\right) & =E_{\text {inc }, e}\left(\theta_{0}\right)+E_{d}\left(\theta_{0}\right) \\
& =E_{\text {inc }, e}\left(\theta_{0}\right)+k^{2} \times \int_{\Omega} G\left(\mathbf{r}-\mathbf{r}^{\prime}\right) \chi\left(\mathbf{r}^{\prime}\right) E\left(\mathbf{r}^{\prime}\right) d \mathbf{r}^{\prime} \\
& =E_{\text {inc }, e}\left(\theta_{0}\right)+A_{e}[\chi E], \mathbf{r} \in \Gamma
\end{aligned}
$$

in which $k=\omega \sqrt{\mu_{0} \varepsilon_{b}}$, Green's function $G\left(\mathbf{r}-\mathbf{r}^{\prime}\right)=$ $-(j / 4) H_{0}^{(2)}\left(k\left|\mathbf{r}-\mathbf{r}^{\prime}\right|\right)\left(H_{0}^{(2)}\right.$ is a Hankel function of zero order and second kind ), contrast function $\chi(\cdot)=\left[\varepsilon_{r}(\cdot)-1\right]$ and objects' dielectric permittivity $\varepsilon_{r}(\mathbf{r}) \varepsilon_{\mathbf{b}}$. In the above two formulas, $E_{d}$ is the scattered field needed to be reconstructed. Moreover, integral operators $A_{i}, A_{e}$, incident fields $E_{\text {inc, } i}$, $E_{\text {inc, } e}$ and total fields $E, E_{\text {tot }}$ are the quantities evaluated in $\Omega$ and observation circle, respectively.

The considered problem herein amounts to retrieving $E_{d}\left(\theta_{0}\right)$ from the knowledge of $E_{\text {inc, } e}\left(\theta_{0}\right)$ and $\left|E_{\text {tot }}\left(\theta_{0}\right)\right|^{2}$. In order to solve the phase reconstruction problem, a sequence of non-linear equations will be constructed. However if the number of variables to be solved is similar to or larger than the number of equations, the problem will be underdetermined, which will make the solution non-unique. Thus, we should find the key variables, which are called degrees of freedom, inside 
the equations to reduce the number of variables to be solved. This is our way to deal with phase reconstruction.

\section{A. Fourier Harmonics}

The $B(\cdot)$ operator, related to the scattered field defined by [169], is defined as:

$$
\mathrm{B}\left[E_{d}\left(\theta_{0}\right)\right]=\left|E_{d}\left(\theta_{0}\right)\right|^{2}+2 \operatorname{Re}\left[E_{d}\left(\theta_{0}\right) E_{\text {inc }, e}\left(\theta_{0}\right)^{*}\right]
$$

in which $*$ stands for matrix conjugate, and can be rewritten as

$$
\mathrm{B}\left[E_{d}\left(\theta_{0}\right)\right]=\left|E_{\mathrm{tot}}\left(\theta_{0}\right)\right|^{2}-\left|E_{\mathrm{inc}, e}\left(\theta_{0}\right)\right|^{2} .
$$

It has been thoroughly shown [113] that the scattered field under the above scenario can be accurately represented with $2 k a$ Fourier harmonics. Thus the scattered field

$$
E_{d}\left(\theta_{0}\right)=\sum_{n=-k a}^{k a} c_{n} e^{j n \theta_{0}}=\sum_{n=-k a}^{k a}\left(x_{n}+j y_{n}\right) e^{j n \theta_{0}}
$$

in which $c_{n}=x_{n}+j y_{n}$. The Fourier harmonic coefficients $x_{n}$ and $y_{n}$ are the actual variables which are going to be retrieved. A series of nonlinear equations will be established by substituting Fourier series expansion Eq. (5) of scattered fields into Eq. (3) with the equation number equal to $L$. In order to make the problem overdetermined, the variable's number of $4 k a+2$ should be less than $L$. The built-in MATLAB function fsolve will be applied to give the solution to the established non-linear equations.

\section{B. Radiating Currents}

The radiating currents exhibits finite degrees of freedom, the number of which is bounded by the number of dominant singular values of the Green's function [213].

Define,

$$
c(\mathbf{r})=\chi(\mathbf{r}) E(\mathbf{r}), \mathbf{r} \in \Omega
$$

The investigated domain is divided into $N$ small areas. In each small area $\Delta \Omega, c(\mathbf{r})$ is assumed to be identical. Thus, Eq. (2) can be represented as the matrix format,

$$
\begin{gathered}
\mathbf{E}_{\mathrm{tot}}=\mathbf{E}_{\mathrm{inc}, e}+\mathbf{E}_{d} \\
\mathbf{E}_{d}=\mathbf{G c}
\end{gathered}
$$

and

$$
(\mathbf{G})_{i, j}=k^{2} \times \int_{\Delta \Omega} G\left(\mathbf{r}_{i}-\mathbf{r}_{j}^{\prime}\right) d \mathbf{r}_{j}^{\prime}
$$

where $(\mathbf{G})_{i, j}$ denotes the $i$-th row and $j$-th column in the matrix G. $\mathbf{r}_{i}$ denotes the $i$-th measurement and $\mathbf{r}_{j}^{\prime}$ denotes the $j$-th small area in the investigated domain $\Omega$.

The singular value decomposition (SVD) of $\mathbf{G}$ is,

$$
\mathbf{G}=\mathbf{U} \boldsymbol{\Lambda} \mathbf{V}^{H}
$$

where $H$ means transpose conjugate operator.

Assume the number of dominant singular values of $\mathbf{G}$ is $M$, then

$$
\mathbf{G} \approx \mathbf{U}_{M} \boldsymbol{\Lambda}_{M} \mathbf{V}_{M}^{H}
$$

where $\mathbf{U}_{M}$ and $\mathbf{V}_{M}$ are the first $M$ columns of $\mathbf{U}$ and $\mathbf{V}$ respectively. Besides,

$$
\boldsymbol{\Lambda}_{M}=\left[\begin{array}{lll}
\lambda_{1} & & \\
& \ddots & \\
& & \lambda_{M}
\end{array}\right]
$$

where $\lambda_{1} \geq \lambda_{2} \geq \cdots \geq \lambda_{M}>0$.

Define

$$
\mathbf{x}=\mathbf{V}_{M}^{H} \mathbf{c}
$$

then

$$
\mathbf{E}_{d} \approx \mathbf{U}_{M} \boldsymbol{\Lambda}_{M} \mathbf{x}
$$

It is easy to see that part of $\mathbf{c}$ contributes to the scattered field, which can be called a radiating current [213].

Thus,

$$
\mathbf{E}_{\text {tot }} \approx \mathbf{E}_{\mathrm{inc}, e}+\mathbf{U}_{M} \boldsymbol{\Lambda}_{M} \mathbf{x}
$$

and the non-linear equations can be obtained as,

$$
\left|\mathbf{E}_{\text {inc }, e}+\mathbf{U}_{M} \boldsymbol{\Lambda}_{M} \mathbf{x}\right|^{2}-\left|\mathbf{E}_{\text {tot }}\right|^{2}=\mathbf{0}
$$

There are $L$ equations and $M$ variables to be solved in the above non-linear equations. Meanwhile $M$ is less than $L$.

Besides, following [213], in order to solve the phase reconstruction problem, a cost function can be defined as,

$$
f(\mathbf{x})=\sum_{l=1}^{L}\left(\left|\left(\mathbf{E}_{\mathrm{inc}, e}+\mathbf{U}_{M} \boldsymbol{\Lambda}_{M} \mathbf{x}\right)_{l, 1}\right|^{2}-\left|\left(\mathbf{E}_{\mathrm{tot}}\right)_{l, 1}\right|^{2}\right)^{2}
$$

The conjugate gradient method can be used to obtain the optimal value of $\mathbf{x}$ [213]. Then the scattered field can be reconstructed.

\section{Numerical Results}

The phase retrieval results obtained by aforementioned algorithms will be shown. The experimental data is provided by Institute Fresnel in France [168]. The file name is FoamDielIntTM.exp. The working frequency is $2 \mathrm{GHz}$. $a=0.15 \mathrm{~m} . b=1.67 \mathrm{~m} . \theta_{i}=0^{\circ} . \theta_{0}$ is from $60^{\circ}$ to $300^{0}$ with $1^{\circ}$ interval. Thus, $L$ is equal to 241 and $\mathrm{M}$ is chosen to be 10. The reconstruction results are shown in Fig. 2 and Fig. 3 for phase and amplitude respectively. The reconstructed scattered field is very close to the true (measured) scattered field.

\section{FUTURE WORK}

This series [4], [5] describes a new initiative to bring together two areas: wireless communications and radio frequency tomography. Although this vision seems natural, a systematic attack to this problem is for the first time presented here. The focus is to design a system that works. No effort is made to optimize this system design, or the algorithms. We emphasize the system engineering approach in our work. The architecture of a phase reconstruction algorithm to retrieve the phase of a communications signal, combined with time reversal imaging, seems promising at this point. 


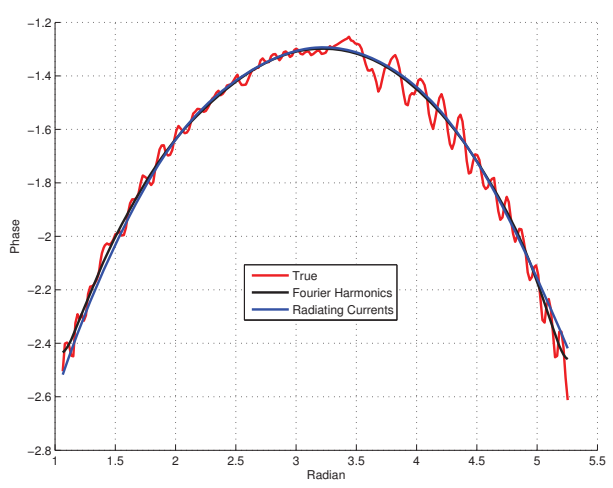

Fig. 2. Phase reconstruction.

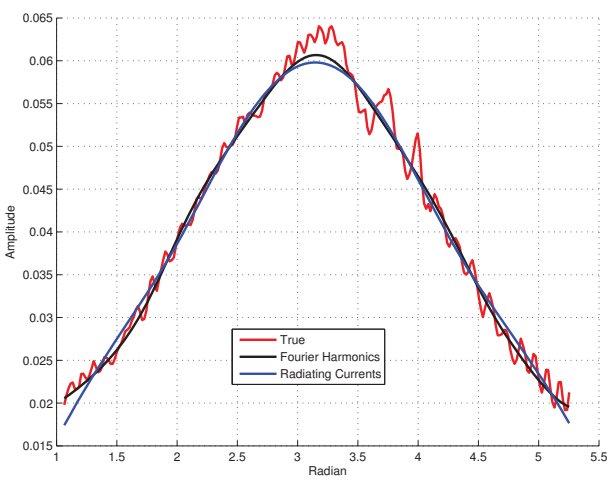

Fig. 3. Amplitude reconstruction.

Experimental data for extended targets have been used for phase retrieval in this paper. Also, two different algorithms are implemented to test this concept. A literature and history extending back more three decades has been exploited in our research and system architecture.

What is missing is a software-defined radio to measure the amplitude of the signal, and to confirm the phase retrieval algorithm. If the amplitude measurement is sufficiently accurate, the algorithm is expected to work. If not, these measurements errors must be accounted for, by regarding them as "noise". Very likely, the errors (noise) are so large that a low signal to noise ratio is resultant. Fortunately, the time reversal matrix (operator) has the capability to filter these errors. The leading eigenvectors - obtained via principal components using dimensionality reduction in machine learningare of interest. This practical system requirement ties together machine learning and low energy signal detection problem.

Sampling is critical to tomography. Close-in sensing is required to achieve high quality signal measurements [1]. Mathematically, the problem at hand is to retrieve the informational degrees of freedom. Compressive sensing is naturally connected to this problem; Signal, noise, sampling, and computing are all tied together.

On the other hand, wireless communication is moving to the era of cognitive radio and the use of dynamic spectrum access. Frequency diversity systems allow agile sensing in the presence of interference [1]. NC-OFDM is the scheme of choice in cognitive radio. Future networks will use this scheme [10].
The system engineering challenges have been addressed in Part II [5], of this series. In particular, NC-OFDM is used for spectrum fragmentation of the transmitted waveform to sense the environment. Waveform diversity and optimization are needed to achieve optimal imaging formation - the use of mutual information as the criteria simplifies the problem but may be suboptimal in terms of imaging formation.

Once phase is retrieved, standard coherent tomographic processing is followed. Time reversal imaging has been applied for coherent imaging. We can apply the method in [199] that exploits multipath in a wideband system. Ray-tracing method [325] can be applied. Maximum likelihood estimation of object location can be applied for strongly scattering objects [326]-[330].

Time reversal imaging is valid for inhomogeneous random medium. Basically, if the Green's function of background medium is known, the problem is solved. The phase retrieval problem in inhomogeneous random medium seems be unsolved. In principle, the two algorithms in Section III are valid since only Green's functions are used.

A hardware testbed is under development at TTU. U1timately, wireless tomography will be implemented in this cognitive radio testbed [10].

\section{CONCLUSiON}

Wireless tomography is a novel approach to remote sensing. This idea-combining wireless communications and remote sensing - is based on many years research insight. The methodology, literature review and related work, and system engineering are presented. When only communications components are used for system development, the phase of the signal is either inaccurate or very expensive to obtain.

We suggest a self-coherent wireless tomography, which has two steps. First, the phase retrieval is achieved using amplitude only data that are obtained through wireless sensors. Second, standard radio tomographic imaging algorithms are used. We emphasize time reversal imaging for two reasons: (1) TTU has a working experimental testbed; (2) this technique is the stateof-the-art. Our goal is to demonstrate the concept as quick as possible. No attempt has been made to optimize the system design and the algorithms.

\section{ACKNOWLEDGMENT}

This work is done during Qiu's and Li's visit at AFRL, Rome, NY, funded under 2010 Air Force Summer Faculty Fellowship Program (SFFP). This work is funded by National Science Foundation through grants (ECCS-0901420), (ECCS0821658), and (ECCS-0622125), Office of Naval Research through a grant (N00014-07-1-0529) and a DURIP grant (N00010-10-1-0810), and 2010 Defensive Earmark Project. Helpful technical discussions are appreciated, with government employees Santanu K. Das, Brian Sadler, Robert Ulman, Robert Headrick, Vasu Chakravarthy, Kelvin M. Magde, Lee Lihyeh Liou, David Lin, Thomas Dalrymple, Stephen Hary, and Seng Hong. 


\section{REFERENCES}

[1] M. Wicks, "Spectrum crowding and cognitive radio," in The 2nd International Workshop on Cognitive Information Processing, June 1416 2010. Keynote speaker talk.

[2] F. C. C. (FCC), "National Broadband Plan." http://www.broadband.gov/plan/executive-summary, 2010.

[3] R. C. Qiu, Cognitive Radio Communications and Networking: Principles and Practice. John Wiley and Sons, 2011. 600 pages.

[4] R. Qiu, M. Wicks, Z. Hu, L. Li, and S. Hou, "Wireless Tomography (1): A NovelApproach to Remote Sensing," in 5th International Waveform Diversity \& Design Conference, 2010.

[5] R. Qiu, Z. Hu, M. Wicks, L. Li, S. Hou, and L. Gary, "Wireless Tomography (2): A System Engineering Approach," in 5th International Waveform Diversity \& Design Conference, 2010.

[6] R. C. Qiu, N. Guo, H. Li, Z. Q. Wu, V. Chakravarthy, Y. Song, Z. Hu, P. Zhang, , and Z. Chen, "A Unified Multi-Functional Dynamic Spectrum Access Framework: Tutorial, Theory and Multi-GHz Wideband Testbed," Sensors, vol. 8, pp. 6530-6603, August 2009.

[7] R. Qiu, "A Cognitive Radio Network Testbed." Proposal to Office of Naval Research (ONR), September 2010. Currently Funded.

[8] R. C. Qiu, "Smart Grid Research At TTU." Presented at Argonne National Laboratory, Feb. 2010. available at http://iweb.tntech.edu/rqiu/publications.htm.

[9] R. C. Qiu, "Cognitive Radio and Smart Grid." IEEE Chapter, Huntsville, Alabama, Feb. 18 2010. available at http://iweb.tntech.edu/rqiu/publications.htm.

[10] R. Qiu, Z. Chen, N. Guo, Y. Song, P. Zhang, H. Li, and L. Lai, "Towards A Real-time Cognitive Radio Network Testbed: Architecture, Hardware Platform, and Application to Smart Grid," in Fifth IEEE Workshop on Networking Technologies for Software-Defined Radio and White Space (IEEE SECON), (Boston, MA,), June 2010.

[11] J. Reed, "Enabling Rural Virginias Smart Grid through White Space Communications." Website. two pages.

[12] M. Wicks, "Rf tomography with application to ground penetrating radar," in Conference Record of the Forty-First Asilomar Conference on Signals, Systems and Computers, 2007. ACSSC 2007, pp. 2017-2022, 2007.

[13] Ettus, “Usrp2.” http://www.ettus.com/, May 2010. Ettus Research LLC.

[14] J. Wilson and N. Patwari, "Radio tomographic imaging with wireless networks," IEEE Trans. Mobile Computing, 2009.

[15] N. Patwari and P. Agrawal, "Effects of correlated shadowing: Connectivity, localization, and RF tomography," in Proceedings of the 7th international conference on Information processing in sensor networks, pp. 82-93, IEEE Computer Society, 2008.

[16] N. Patwari, J. Ash, S. Kyperountas, A. Hero III, R. Moses, and N. Correal, "Locating the nodes: cooperative localization in wireless sensor networks," IEEE Signal Processing Magazine, vol. 22, no. 4, pp. 54-69, 2005 .

[17] M. Cover, K. Kanukurthy, and D. Andersen, "Microwave tomography using dynamic 802.15. 4 wireless networks," in 2007 IEEE International Conference on Electro/Information Technology, pp. 251-256, 2007.

[18] A. C. Kak and M. Slaney, Principles of Computerized Tomographic Imaging. IEEE Press, 1988.

[19] F. Natterer and F. Wuebbeling, Mathematical Methods in Image Reconstruction. SIAM, 2001.

[20] M. Wicks, B. Himed, J. Bracken, H. Bascom, and J. Clancy, "Ultra narrow band adaptive tomographic radar," in 2005 1st IEEE International Workshop on Computational Advances in Multi-Sensor Adaptive Processing, pp. 36-39, 2005.

[21] J. Norgard, R. Musselman, and A. Drozd, "Three-dimensional Microwave Tomography: Waveform diversity and distributed sensors for detecting and imaging buried objects with suppressed electromagnetic interference," in Asia-Pacific Symposium on Electromagnetic Compatibility and 19th International Zurich Symposium on Electromagnetic Compatibility, 2008. APEMC 2008, pp. 371-374, 2008.

[22] J. Parker and J. Norgard, "Autofocusing for RF tomography using particle swarm optimization," in IEEE Radar Conference, 2008. RADAR'08, pp. 1-6, 2008.

[23] I. Bradaric, G. Capraro, and M. Wicks, "Waveform diversity for different multistatic radar configurations," in Conference Record of the Forty-First Asilomar Conference on Signals, Systems and Computers, 2007. ACSSC 2007, pp. 2038-2042, 2007.
[24] I. Bradaric, G. Capraro, M. Wicks, and P. Zulch, "Signal processing and waveform selection strategies in multistatic radar systems," in Waveform Diversity and Design Conference, 2007. International, pp. 307311, 2007.

[25] M. Wicks, K. Magde, and P. Antonik, "Waveform diversity for distributed and layered sensing," in 2007 IET International Conference on Radar Systems, pp. 1-5, 2007.

[26] M. Wicks, K. Magde, W. Moore, and J. Norgard, "Adaptive MultiSensor Waveform Design for RF Tomographic Sensors," in International Conference on Electromagnetics in Advanced Applications, 2007. ICEAA 2007, pp. 423-426, 2007.

[27] I. Bradaric, G. Capraro, D. Weiner, and M. Wicks, "A framework for the analysis of multistatic radar systems with multiple transmitters," in Proceedings of the International Conference on Electromagnetics in Advanced Applications ICEAA 2007, pp. 17-21, 2007.

[28] M. Wicks, "A Brief History of Waveform Diversity," in NATO SET-119 Waveform Diversity for Advanced Systems, (Dayton, Ohio), July 16-17 2010.

[29] G. Capraro, I. Bradaric, and M. Wicks, "Waveform diversity in distributed radar," in International Conference on Electromagnetics in Advanced Applications, 2009. ICEAA'09, pp. 954-957, 2009.

[30] G. Capraro, M. Wicks, and M. Szczepanski, "Waveform Diversity and Knowledge Based Signal Processing in Distributed Radar,"

[31] S. Out, "RF Tomography for Below-Ground Imaging of Extended Areas and Close-in Sensing," IEEE Geoscience and Remote Sensing Letters, pp. 496-500.

[32] L. Monte, D. Erricolo, F. Soldovieri, and M. Wicks, "Radio Frequency Tomography for Tunnel Detection," IEEE Trans. Geoscience Remote Sensing, vol. 48, pp. 1128-1137, 2010.

[33] M. D’Urso, K. Belkebir, L. Crocco, T. Isernia, and A. Litman, "Phaseless imaging with experimental data: facts and challenges," Journal of the Optical Society of America A, vol. 25, no. 1, pp. 271-281, 2008.

[34] L. Taylor, "The phase retrieval problem," IEEE Transactions on Antennas and Propagation, vol. 29, no. 2, pp. 386-391, 1981.

[35] J. Fienup, "Phase retrieval algorithms: a comparison," Applied Optics, vol. 21, no. 15, pp. 2758-2769, 1982.

[36] D. Morris, "Phase Retrieval in the Radio Holography of Reflector Antennas and Radio Telescopes," IEEE Trans. Ant. Prop., vol. 33, pp. 749-755, July 1983 .

[37] A. Levi and H. Stark, "Image restoration by the method of generalized projections with application to restoration from magnitude," Journal of the Optical Society of America A, vol. 1, no. 9, pp. 932-943, 1984.

[38] T. Vu, "Null steering by controlling current amplitudes only," in Antennas and Propagation Society International Symposium, 1984, pp. 811-814, 1984.

[39] A. Anderson and S. Sali, "New possibilities for phaseless microwave diagnostics. Part1: Error reduction techniques," in IEE Proceedings $H$ Microwaves, Antennas and Propagation, vol. 132, pp. 291-298, 1985.

[40] R. Barakat and G. Newsam, "Algorithms for reconstruction of partially known, band-limited Fourier-transform pairs from noisy data," Journal of the Optical Society of America A, vol. 2, no. 11, pp. 2027-2039, 1985.

[41] K. Chalasinska-Macukow and H. Arsenault, "Fast iterative solution to exact equations for the two-dimensional phase-retrieval problem," JOSA A, vol. 2, no. 1, pp. 46-50, 1985.

[42] S. Sali, "New possibilities for phaseless microwave diagnostics. Part2: The uniqueness problem and half plane imaging," in IEE Proceedings $H$ Microwaves, Antennas and Propagation, vol. 132, pp. 299-306, 1985.

[43] J. Sanz and T. Huang, "Polynomial system of equations and its applications to the study of the effect of noise on multidimensional Fourier transform phase retrieval from magnitude," IEEE transactions on acoustics, speech, and signal processing, vol. 33, no. 4, pp. 9971004, 1985.

[44] J. Fienup, "Phase retrieval using boundary conditions," Journal of the Optical Society of America A, vol. 3, no. 2, pp. 284-288, 1986.

[45] J. Fienup and C. Wackerman, "Phase-retrieval stagnation problems and solutions," Journal of the Optical Society of America A, vol. 3, no. 11, pp. 1897-1907, 1986

[46] O. Bucci and G. Franceschetti, "On the spatial bandwidth of scattered fields," IEEE transactions on antennas and propagation, vol. 35, no. 12, pp. $1445-1455,1987$.

[47] J. Cederquist and C. Wackerman, "Phase-retrieval error: a lower bound," Journal of the Optical Society of America A, vol. 4, no. 9, pp. 1788-1792, 1987. 
[48] T. Crimmins, "Phase retrieval for discrete functions with support constraints," Journal of the Optical Society of America A, vol. 4, no. 1, pp. 124-134, 1987.

[49] J. Fienup, "Reconstruction of a complex-valued object from the modulus of its Fourier transform using a support constraint," Journal of the Optical Society of America A, vol. 4, no. 1, pp. 118-123, 1987.

[50] R. Gonsalves, "Phase retrieval by differential intensity measurements," Journal of the Optical Society of America A, vol. 4, no. 1, pp. 166-170, 1987

[51] T. Huang, K. Rinaldi, and H. Lee, "Comparison of phase retrieval algorithms," in Acoustics, Speech, and Signal Processing, IEEE International Conference on ICASSP'87., vol. 12, 1987.

[52] R. Lane, W. Fright, and R. Bates, "Direct phase retrieval," IEEE Transactions on Acoustics, Speech and Signal Processing, vol. 35 no. 4, pp. 520-526, 1987.

[53] G. Liu and P. Scott, "Phase retrieval and twin-image elimination for in-line Fresnel holograms," Journal of the Optical Society of America $A$, vol. 4, no. 1, pp. 159-165, 1987 .

[54] N. Nakajima, "Phase retrieval from two intensity measurements using the Fourier series expansion," Journal of the Optical Society of America $A$, vol. 4 , no. 1 , pp. $154-158,1987$.

[55] O. Yamagami, "Phase-retrieval algorithms for nonnegative and finiteextent objects," J. Opt. Soc. Am. A, vol. 4, pp. 720-726, 1987.

[56] A. Anderson, J. McCormack, and G. Junkin, "Phase retrieval enhancement of antenna metrology data," Electronics Letters, vol. 24, no. 19, pp. 1243-1244, 1988.

[57] N. Nakajima, "Phase retrieval using the logarithmic Hilbert transform and the Fourier-series expansion," Journal of the Optical Society of America A, vol. 5, no. 2, pp. 257-262, 1988.

[58] M. Nieto-Vesperinas, R. Navarro, and F. Fuentes, "Performance of a simulated-annealing algorithm for phase retrieval," J. Opt. Soc. Am. A, vol. 5, pp. 30-38, 1988 .

[59] K. Richardson, "Probabilistic algorithm for phase retrieval," J. Opt. Soc. Am. A, vol. 5, pp. 993-998, 1988

[60] S. Sali, "Phase retrieval in a lossy medium," Electronics Letters, vol. 24, no. 2, pp. 131-132, 1988

[61] S. Sali, "Phase-retrieval technique for antenna metrology," Electronics Letters, vol. 24, no. 2, pp. 132-133, 1988.

[62] M. Slaney and A. Kak, Principles of computerized tomographic imaging. IEEE Press, 1988.

[63] A. Anderson, G. Junkin, and J. McCormack, "Near-field far-field predictions from single-intensity-planar-scan phase retrieval," Electronics Letters, vol. 25, p. 519, 1989.

[64] O. Bucci and G. Franceschetti, "On the degrees of freedom of scattered fields," IEEE transactions on Antennas and Propagation, vol. 37, no. 7, pp. 918-926, 1989.

[65] R. Bates, B. Quek, and C. Parker, "Some implications of zero sheets for blind deconvolution and phase retrieval," Journal of the Optical Society of America A, vol. 7, no. 3, pp. 468-479, 1990.

[66] O. Bucci, G. D’ELIA, G. Leone, and R. Pierri, "Far-field pattern determination from the near-field amplitude on two surfaces," IEEE transactions on antennas and propagation, vol. 38, no. 11, pp. 1772 1779, 1990.

[67] T. Crimmins, J. Fienup, and B. Thelen, "Improved bounds on object support from autocorrelation support and application to phase retrieval," Journal of the Optical Society of America A, vol. 7, no. 1, pp. 3-13, 1990.

[68] J. Fienup and A. Kowalczyk, "Phase retrieval for a complex-valued object by using a low-resolution image," Journal of the Optical Society of America A, vol. 7, no. 3, pp. 450-458, 1990.

[69] G. Junkin, "Microwave metrology of reflector antennas from a single amplitude," 1990.

[70] W. Kim and M. Hayes, "Phase retrieval using two Fourier-transform intensities," Journal of the Optical Society of America A, vol. 7, no. 3, pp. 441-449, 1990.

[71] R. Millane, "Phase retrieval in crystallography and optics," Journal of the Optical Society of America A, vol. 7, no. 3, pp. 394-411, 1990.

[72] M. Pérez-Ilzarbe, M. Nieto-Vesperinas, and R. Navarro, "Phase retrieval from experimental far-field intensity data," Journal of the Optical Society of America A, vol. 7, no. 3, pp. 434-440, 1990.

[73] Y. Rolain, R. Pintelon, and J. Schoukens, "Amplitude-only versus amplitude-phase estimation," IEEE Transactions on Instrumentation and Measurement, vol. 39, no. 6, pp. 818-823, 1990.
[74] J. Seldin and J. Fienup, "Iterative blind deconvolution algorithm applied to phase retrieval," Journal of the Optical Society of America A, vol. 7, no. 3, pp. 428-433, 1990

[75] J. Seldin and J. Fienup, "Numerical investigation of the uniqueness of phase retrieval," Journal of the Optical Society of America A, vol. 7, no. 3, pp. 412-427, 1990.

[76] G. Yanchang and L. Jianxin, "Real amplitude-only nulling algorithm (RAMONA) for adaptive digital beamforming," in Antennas and Propagation Society International Symposium, 1990. AP-S. Merging Technologies for the 90's. Digest., pp. 206-209, 1990.

[77] T. Isernia, R. Pierri, and G. Leone, "New technique for estimation of farfield from near-zone phaseless data," Electronics letters, vol. 27, p. $652,1991$.

[78] E. Lantz, "Retrieval of a phase-and-amplitude submicrometric object from images obtained in partially coherent microscopy," Journal of the Optical Society of America A, vol. 8, no. 5, pp. 791-800, 1991.

[79] M. Nieto-Vesperinas, "Phase retrieval of photon-limited stellar images from information of the power spectrum only," J. Opt. Soc. Am. A, vol. 8, pp. 908-918, 1991.

[80] C. Wackerman and A. Yagle, "Use of Fourier domain real-plane zeros to overcome a phase retrieval stagnation," Journal of the Optical Society of America A, vol. 8, no. 12, pp. 1898-1904, 1991.

[81] R. Barakat and B. Sandler, "Determination of the wave-front aberration function from measured values of the point-spread function: a twodimensional phase retrieval problem," Journal of the Optical Society of America A, vol. 9, no. 10, pp. 1715-1723, 1992.

[82] A. Devaney, "Diffraction tomographic reconstruction from intensity data," IEEE Transactions on Image Processing, vol. 1, no. 2, pp. 221228, 1992.

[83] D. Dobson, "Phase reconstruction via nonlinear least-squares," Inverse Problems, vol. 8, p. 541, 1992.

[84] T. Isernia, G. Leone, and R. Pierri, "New approach to antenna testing from near field phaseless data-The cylindrical scanning," in IEE Proceedings H: Microwaves Antennas and Propagation, vol. 139, pp. 363368, 1992.

[85] M. Maleki, A. Devaney, and A. Schatzberg, "Tomographic reconstruction from optical scattered intensities," Journal of the Optical Society of America A, vol. 9, no. 8, pp. 1356-1363, 1992.

[86] M. Pérez-Ilzarbe, "Phase retrieval from the power spectrum of a periodic object," Journal of the Optical Society of America A, vol. 9, no. 12 , pp. $2138-2148,1992$.

[87] A. Tennant, G. Junkin, and A. Anderson, "Antenna far-field predictions from two phaseless cylindrical near-field measurements," Electronics Letters, vol. 28, p. 2120, 1992.

[88] V. Vanov, V. Sivokon, and M. Vorontsov, "Phase retrieval from a set of intensity measurements: theory and experiment," Journal of the Optical Society of America A, vol. 9, no. 9, pp. 1515-1524, 1992.

[89] J. Fienup, "Phase-retrieval algorithms for a complicated optical system," Applied Optics, vol. 32, no. 10, pp. 1737-1746, 1993.

[90] T. Isernia, G. Leone, and R. Pierri, "Antenna testing from phaseless measurements: probe compensation and experimental results in the cylindrical case," IEE proceedings. Part H. Microwaves, antennas and propagation, vol. 140, no. 5, pp. 395-400, 1993.

[91] T. Isernia, G. Leone, and R. Pierri, "Results for a truncated phaseless near field technique," Electronics Letters, vol. 29, no. 5, pp. 505-506, 1993.

[92] G. James, G. Poulton, and P. McCulloch, "Panel setting from microwave holography by the method of successiveprojections," IEEE Transactions on Antennas and Propagation, vol. 41, no. 11, pp. 15231529, 1993.

[93] M. Maleki and A. Devaney, "Phase-retrieval and intensity-only reconstruction algorithms for optical diffraction tomography," Journal of the Optical Society of America A, vol. 10, no. 5, pp. 1086-1092, 1993.

[94] R. Trebino and D. Kane, "Using phase retrieval to measure the intensity and phase of ultrashort pulses: frequency-resolved optical gating," Journal of the Optical society of America A, vol. 10, no. 5, pp. 11011111, 1993.

[95] G. Poulton, "Array pattern estimation from amplitude measurements on arbitrary near-field surfaces," in Proceedings of the Acoustics, Speech, and Signal Processing, 1994. on IEEE International ConferenceVolume 04, pp. 241-244, IEEE Computer Society, 1994

[96] C. Wackerman and A. Yagle, "Phase retrieval and estimation with use of real-plane zeros," Journal of the Optical Society of America $A$, vol. 11, no. 7, pp. 2016-2026, 1994. 
[97] P. Bones, C. Parker, B. Satherley, and R. Watson, "Deconvolution and phase retrieval with use of zero sheets," Journal of the Optical Society of America A, vol. 12, no. 9, pp. 1842-1857, 1995.

[98] T. Gureyev, A. Roberts, and K. Nugent, "Phase retrieval with the transport-of-intensity equation: matrix solution with use of Zernike polynomials," Journal of the Optical Society of America A, vol. 12, no. 9, pp. 1932-1942, 1995.

[99] T. Isernia, G. Leone, and R. Pierri, "Phase retrieval of radiated fields," Inverse Problems, vol. 11, p. 183, 1995.

[100] V. Schejbal, "Phase Difference Between Linear Components of Elliptically Polarized Waves from Amplitude-Only Measurements," IEEE Antennas and Propagation Magazine, vol. 37, no. 4, p. 69, 1995.

[101] V. Voitsekhovich, "Phase-retrieval problem and orthogonal expansions: curvature sensing," Journal of the Optical Society of America A, vol. 12 no. 10, pp. 2194-2202, 1995.

[102] P. Chen, M. Fiddy, C. Liao, and D. Pommet, "Blind deconvolution and phase retrieval from point zeros," Journal of the Optical Society of America A, vol. 13, no. 7, pp. 1524-1531, 1996.

[103] T. Gureyev and K. Nugent, "Phase retrieval with the transport-ofintensity equation. II. Orthogonal series solution for nonuniform illumination," Journal of the Optical Society of America A, vol. 13, no. 8 , pp. 1670-1682, 1996.

[104] T. Isernia, G. Leone, and R. Pierri, "Radiation pattern evaluation from near-field intensities on planes," IEEE Transactions on Antennas and Propagation, vol. 44, no. 5, 1996.

[105] T. Isernia, F. Soldovieri, G. Leone, and R. Pierri, "On the local minima in phase reconstruction algorithms," Radio Science, vol. 31, no. 6 , pp. 1887-1899, 1996.

[106] G. Leone, R. Pierri, and F. Soldovieri, "Reconstruction of complex signals from intensities of Fourier-transform pairs," Journal of the Optical Society of America A, vol. 13, no. 7, pp. 1546-1556, 1996.

[107] B. Dong, Y. Zhang, B. Gu, and G. Yang, "Numerical investigation of phase retrieval in a fractional Fourier transform," Journal of the Optical Society of America A, vol. 14, no. 10, pp. 2709-2714, 1997.

[108] T. Isernia, V. Pascazio, and R. Pierri, "A nonlinear estimation method in tomographic imaging," IEEE Transactions on Geoscience and Remote Sensing, vol. 35, no. 4, pp. 910-923, 1997.

[109] G. Leone and R. Pierri, "Reflector antenna diagnosis from phaseless data," IEEE Transactions on Antennas and Propagation, vol. 45, no. 8, pp. 1236-1244, 1997.

[110] R. Pierri and A. Tamburrino, "On the local minima problem in conductivity imaging via a quadratic approach," Inverse Problems, vol. 13, p. 1547, 1997

[111] H. Takajo, T. Takahashi, H. Kawanami, and R. Ueda, "Numerical investigation of the iterative phase-retrieval stagnation problem: territories of convergence objects and holes in their boundaries," Journal of the Optical Society of America A, vol. 14, no. 12, pp. 3175-3187, 1997.

[112] T. Takenaka, D. Wall, H. Harada, and M. Tanaka, "Reconstruction algorithm of the refractive index of a cylindrical object from the intensity measurements of the total field," Microwave and optical technology letters, vol. 14, no. 3, pp. 182-188, 1997.

[113] O. Bucci, C. Gennarelli, and C. Savarese, "Representation of electromagnetic fields over arbitrary surfaces bya finite and nonredundant number of samples," IEEE Transactions on Antennas and Propagation, vol. 46, no. 3, pp. 351-359, 1998.

[114] I. Iglesias, N. López-Gil, and P. Artal, "Reconstruction of the pointspread function of the human eye from two double-pass retinal images by phase-retrieval algorithms," J. Opt. Soc. Am. A, vol. 15, pp. 326$339,1998$.

[115] R. Irwan and R. Lane, "Phase retrieval with prior information," Journal of the Optical Society of America A, vol. 15, no. 9, pp. 2302-2311, 1998.

[116] J. Miao, D. Sayre, and H. Chapman, "Phase retrieval from the magnitude of the Fourier transforms of nonperiodic objects," Journal of the Optical Society of America A, vol. 15, no. 6, pp. 1662-1669, 1998.

[117] N. Nakajima, "Phase-retrieval system using a shifted Gaussian filter," Journal of the Optical Society of America-A-Optics Image Science and Vision, vol. 15, no. 2, pp. 402-406, 1998.

[118] T. Sarkar and B. Hu, "Generation of nonminimum phase from amplitude-only data," IEEE Transactions on Microwave Theory and Techniques, vol. 46, no. 8, pp. 1079-1084, 1998

[119] H. Takajo, T. Takahashi, R. Ueda, and M. Taninaka, "Study on the convergence property of the hybrid input-output algorithm used for phase retrieval," Journal of the Optical Society of America A, vol. 15, no. 11 , pp. $2849-2861,1998$.

[120] W. Arrasmith, "Branch-point-tolerant least-squares phase reconstructor," JOSA A, vol. 16, no. 7, pp. 1864-1872, 1999.

[121] O. Bucci, A. Capozzoli, and G. D'Elia, "Regularizing strategy for image restoration and wave-front sensing by phase diversity," Journal of the Optical Society of America A, vol. 16, no. 7, pp. 1759-1768, 1999.

[122] O. Bucci, L. Crocco, and T. Isernia, "Improving the reconstruction capabilities in inverse scattering problems by exploitation of closeproximity setups," Journal of the Optical Society of America A, vol. 16, no. 7, pp. 1788-1798, 1999.

[123] O. Bucci, G. DElia, and M. Migliore, "An effective near-field far-field transformation technique from truncated and inaccurate amplitude-only data," IEEE Transactions on Antennas and Propagation, vol. 47, no. 9, p. $1377,1999$.

[124] S. Caorsi and G. Gragnani, "Inverse-scattering method for dielectric objects based on the reconstruction of the nonmeasurable equivalent current density," Radio Science, vol. 34, no. 1, pp. 1-8, 1999.

[125] W. Cong, N. Chen, and B. Gu, "Phase retrieval in the Fresnel transform system: a recursive algorithm," JOSA A, vol. 16, no. 7, pp. 1827-1830, 1999.

[126] M. Fiddy, "Diffraction tomography based on McCutchen's theorem," J. Opt. Soc. Am. A, vol. 16, pp. 1806-1813, 1999.

[127] J. Fienup, "Phase retrieval for undersampled broadband images," JOSA $A$, vol. 16, no. 7, pp. 1831-1837, 1999.

[128] T. Isernia, G. Leone, R. Pierri, and F. Soldovieri, "Role of support information and zero locations in phase retrieval by a quadratic approach," JOSA A, vol. 16, no. 7, pp. 1845-1856, 1999.

[129] K. Larkin and C. Sheppard, "Direct method for phase retrieval from the intensity of cylindrical wave fronts," JOSA A, vol. 16, no. 7, pp. 18381844, 1999.

[130] G. Leone, R. Persico, and R. Pierri, "Inverse scattering under the distorted Born approximation for cylindrical geometries," Journal of the Optical Society of America A, vol. 16, no. 7, pp. 1779-1787, 1999.

[131] N. Nakajima and Y. Tomita, "New approach to determine the intensity and phase of ultrashort pulses by use of time-to-space conversion and a noniterative phase-retrieval algorithm," JOSA A, vol. 16, no. 6 , pp. 1268-1276, 1999.

[132] A. Noushin, M. Fiddy, and J. Graham-Eagle, "Some new findings on the zeros of band-limited functions," JOSA A, vol. 16, no. 7, pp. 1857$1863,1999$.

[133] R. Pierri, G. D’Elia, and F. Soldovieri, “A two probes scanning phaseless near-field far-field transformation technique," IEEE Transactions on Antennas and Propagation, vol. 47, no. 5, pp. 792-802, 1999.

[134] J. Sanchez-de La-Llave, A. Morales-Porras, M. Testorf, R. McGahan, and M. Fiddy, "Nonlinear filtering of backpropagated fields," Journal of the Optical Society of America A, vol. 16, no. 7, pp. 1799-1805, 1999.

[135] H. Takajo, T. Takahashi, and T. Shizuma, "Further study on the convergence property of the hybrid input-output algorithm used for phase retrieval," J. Opt. Soc. Am. A, vol. 16, pp. 2163-2168, 1999.

[136] R. Yaccarino and Y. Rahmat-Samii, "Phaseless bi-polar planar nearfield measurements and diagnostics of array antennas," IEEE Transactions on Antennas and Propagation, vol. 47, no. 3, 1999.

[137] J. Ye, K. Webb, R. Millane, and T. Downar, "Modified distorted Born iterative method with an approximate Fréchet derivative for optical diffusion tomography," JOURNAL-OPTICAL SOCIETY OF AMERICA $A$, vol. 16, pp. 1814-1826, 1999.

[138] O. Bucci, A. Capozzoli, and G. D'elia, "Diagnosis of array faults from far-field amplitude-only data," IEEE Transactions on Antennas and Propagation, vol. 48, no. 5, p. 647, 2000.

[139] O. Bucci, L. Crocco, T. Isernia, and V. Pascazio, "Inverse scattering problems with multifrequency data: reconstruction capabilities and solution strategies," IEEE Transactions on Geoscience and Remote Sensing, vol. 38, no. 4, pp. 1749-1756, 2000.

[140] M. Migliore, F. Soldovieri, and R. Pierri, "Far-field antenna pattern estimation from near-field data using a low-cost amplitude-only measurement setup," IEEE Transactions on Instrumentation and Measurement, vol. 49, no. 1, p. 71, 2000.

[141] O. Bucci, N. Cardace, L. Crocco, and T. Isernia, "Degree of nonlinearity and a new solution procedure in scalar two-dimensional inverse scattering problems," Journal of the Optical Society of America A, vol. 18, no. 8, pp. 1832-1843, 2001. 
[142] S. Costanzo, G. Di Massa, and M. Migliore, "Integrated microstrip probe for phaseless near-field measurements on plane-polar geometry," Electronics Letters, vol. 37, p. 1018, 2001.

[143] A. Tijhuis, K. Belkebir, A. Litman, and B. Hon, "Multiple-frequency distorted-wave Born approach to $2 \mathrm{D}$ inverse profiling," Inverse problems, vol. 17, p. 1635, 2001.

[144] H. Bauschke, P. Combettes, and D. Luke, "Phase retrieval, error reduction algorithm, and Fienup variants: a view from convex optimization," JOSA A, vol. 19, no. 7, pp. 1334-1345, 2002.

[145] E. Bermani, S. Caorsi, and M. Raffetto, "Microwave detection and dielectric characterization of cylindrical objects from amplitude-only data by means of neural networks," IEEE Transactions on Antennas and Propagation, vol. 50, no. 9, pp. 1309-1314, 2002.

[146] W. Chalodhorn and D. DeBoer, "Use of microwave lenses in phase retrieval microwave holography of reflector antennas," IEEE Transactions on Antennas and Propagation, vol. 50, no. 9, 2002.

[147] G. Gbur and E. Wolf, "Diffraction tomography without phase information," Optics letters, vol. 27, no. 21, pp. 1890-1892, 2002.

[148] G. Gbur and E. Wolf, "Hybrid diffraction tomography without phase information," Journal of the Optical Society of America A, vol. 19, no. 11, pp. 2194-2202, 2002.

[149] F. Las-Heras and T. Sarkar, "A direct optimization approach for source reconstruction and NF-FF transformation using amplitude-only data," IEEE Transactions on Antennas and Propagation, vol. 50, no. 4, pp. 500-510, 2002.

[150] J. Barchers, "Rapidly convergent phase-retrieval strategy for use with reflected laser light," JOSA A, vol. 20, no. 6, pp. 1013-1024, 2003.

[151] H. Bauschke, P. Combettes, and D. Luke, "Hybrid projection-reflection method for phase retrieval," JOSA A, vol. 20, no. 6, pp. 1025-1034, 2003.

[152] O. Bucci, A. Capozzoli, and G. D'Elia, "A novel approach to scatterers localization problem," IEEE Transactions on Antennas and Propagation, vol. 51, no. 8, pp. 2079-2090, 2003.

[153] S. Caorsi, A. Massa, M. Pastorino, and A. Randazzo, "Electromagnetic detection of dielectric scatterers using phaseless synthetic and real data and the memetic algorithm," IEEE Transactions on Geoscience and Remote Sensing, vol. 41, no. 12, p. 2745, 2003.

[154] B. Dean and C. Bowers, "Diversity selection for phase-diverse phase retrieval," JOSA A, vol. 20, no. 8, pp. 1490-1504, 2003.

[155] V. Elser, "Phase retrieval by iterated projections," JOSA A, vol. 20, no. 1, pp. 40-55, 2003.

[156] P. Hallbjorner, "Retrieving field magnitude and polarisation ellipse from phaseless measurements of linear polarisations, including error analysis," IEE Proceedings-Microwaves, Antennas and Propagation, vol. 150, p. 28, 2003.

[157] L. Crocco, M. DUrso, and T. Isernia, "Inverse scattering from phaseless measurements of the total field on a closed curve," Journal of the Optical Society of America A, vol. 21, no. 4, pp. 622-631, 2004.

[158] M. Dennison and A. Devaney, "Inverse scattering in inhomogeneous background media: II. Multi-frequency case and SVD formulation," Inverse Problems, vol. 20, p. 1307, 2004.

[159] G. Gbur and E. Wolf, "The information content of the scattered intensity in diffraction tomography," Information Sciences, vol. 162, no. 1, pp. 3-20, 2004.

[160] A. Semichaevsky and M. Testorf, "Phase-space interpretation of deterministic phase retrieval," JOSA A, vol. 21, no. 11, pp. 2173-2179, 2004

[161] C. Sheppard, "Defocused transfer function for a partially coherent microscope and application to phase retrieval," Journal of the Optical Society of America A, vol. 21, no. 5, pp. 828-831, 2004

[162] A. Vertiy, S. Gavrilov, V. Stepanyuk, and I. Voynovskyy, "Throughwall and wall microwave tomography imaging," in IEEE Antennas and Propagation Society International Symposium, 2004, pp. 3087-3090, 2004.

[163] M. Anastasio, D. Shi, Y. Huang, and G. Gbur, "Image reconstruction in spherical-wave intensity diffraction tomography," Journal of the Optical Society of America A, vol. 22, no. 12, pp. 2651-2661, 2005.

[164] A. Baussard, "Inversion of multi-frequency experimental data using an adaptive multiscale approach," Inverse Problems, vol. 21, p. S15, 2005.

[165] S. Costanzo, G. Di Massa, and M. Migliore, “A novel hybrid approach for far-field characterization from near-field amplitude-only measurements on arbitrary scanning surfaces," IEEE Transactions on Antennas and Propagation, vol. 53, no. 6, 2005.
[166] L. Crocco, M. D’Urso, and T. Isernia, "Testing the contrast source extended Born inversion method against real data: the TM case," Inverse Problems, vol. 21, p. S33, 2005.

[167] G. Gbur, M. Anastasio, Y. Huang, and D. Shi, "Spherical-wave intensity diffraction tomography," JOSA A, vol. 22, no. 2, pp. 230-238, 2005.

[168] J. Geffrin, P. Sabouroux, and C. Eyraud, "Free space experimental scattering database continuation: experimental set-up and measurement precision," inverse Problems, vol. 21, p. S117, 2005.

[169] O. Bucci, L. Crocco, M. D’Urso, and T. Isernia, "Inverse scattering from phaseless measurements of the total field on open lines," JOSA A, vol. 23, no. 10, pp. 2566-2577, 2006.

[170] K. Choi, A. Lanterman, and R. Raich, "Convergence of the SchulzSnyder phase retrieval algorithm to local minima," JOSA A, vol. 23, no. 8, pp. $1835-1845,2006$

[171] H. He, "Simple constraint for phase retrieval with high efficiency," JOSA A, vol. 23, no. 3, pp. 550-556, 2006.

[172] A. Litman and K. Belkebir, "Two-dimensional inverse profiling problem using phaseless data," JOSA A, vol. 23, no. 11, pp. 2737-2746, 2006.

[173] A. Souvorov, T. Ishikawa, and A. Kuyumchyan, "Multiresolution phase retrieval in the Fresnel region by use of wavelet transform," JOSA A, vol. 23, no. 2, pp. 279-287, 2006.

[174] M. Testorf, "Inverse scattering method applied to the synthesis of strongly scattering structures," Opt. Express, vol. 14, pp. 2037-2046, 2006.

[175] A. Capozzoli, R. Ciotola, C. Curcio, G. D’Elia, I. De Colibus, A. Liseno, and P. Vinetti, "Characterization of Real-World SteeredBeam Antennas from Amplitude-Only Near-Field Data," IEEE Antennas and Propagation Magazine, vol. 49, no. 6, pp. 113-122, 2007.

[176] A. Capozzoli, G. D'Elia, and A. Liseno, "Phaseless characterisation of compact antenna test ranges," Microwaves, Antennas \& Propagation, IET, vol. 1, no. 4, pp. 860-866, 2007.

[177] W. Chan, M. Moravec, R. Baraniuk, and D. Mittleman, "Terahertz imaging with compressed sensing and phase retrieval," in Conference on Lasers and Electro-Optics, 2007. CLEO 2007, pp. 1-2, 2007.

[178] M. Chiappe and G. Gragnani, "An analytical approach to the reconstruction of the radiating currents in inverse electromagnetic scattering," Microwave and Optical Technology Letters, vol. 49, no. 2, pp. 354-360, 2007.

[179] L. Crocco, M. D’Urso, and T. Isernia, "Faithful non-linear imaging from only-amplitude measurements of incident and total fields," Opt. Express, vol. 15, pp. 3804-3815, 2007.

[180] R. Deming, "Phase retrieval from intensity-only data by relative entropy minimization," Journal of the Optical Society of America A, vol. 24 no. 11, pp. 3666-3679, 2007.

[181] G. Hislop, S. Hay, and A. Hellicar, "Efficient Sampling of Electromagnetic Fields via the Adaptive Cross Approximation," IEEE Transactions on Antennas and Propagation, vol. 55, no. 12, pp. 3721-3725, 2007.

[182] K. Lanterman, "Phase retrieval from noisy data based on minimization of penalized I-divergence," J. Opt. Soc. Am. A, vol. 24, pp. 34-49, 2007.

[183] S. Marchesini, "Phase retrieval and saddle-point optimization," Journal of the Optical Society of America A, vol. 24, no. 10, pp. 3289-3296, 2007.

[184] E. Marengo, R. Hernandez, and H. Lev-Ari, "Intensity-only signalsubspace-based imaging," Journal of the Optical Society of America $A$, vol. 24 , no. 11 , pp. 3619-3635, 2007

[185] S. Razavi and Y. Rahmat-Samii, "A new look at phaseless planar near-field measurements: limitations, simulations, measurements, and a hybrid solution," IEEE Antennas and Propagation Magazine, vol. 49, no. 2, pp. 170-178, 2007.

[186] X. Rondeau, E. Thiébaut, M. Tallon, and R. Foy, "Phase retrieval from speckle images," Journal of the Optical Society of America A, vol. 24, no. 10, pp. 3354-3365, 2007.

[187] P. Bao, F. Zhang, G. Pedrini, and W. Osten, "Phase retrieval using multiple illumination wavelengths," Optics letters, vol. 33, no. 4, pp. 309-311, 2008.

[188] F. Baron, I. Mocoeur, F. Cassaing, and L. Mugnier, "Unambiguous phase retrieval as a cophasing sensor for phased array telescopes," Journal of the Optical Society of America A, vol. 25, no. 5, pp. 1000 $1015,2008$.

[189] M. Fienup, "Phase retrieval with Fourier-weighted projections," J. Opt. Soc. Am. A, vol. 25, pp. 701-709, 2008. 
[190] U. Gopinathan, G. Situ, T. Naughton, and J. Sheridan, "Noninterferometric phase retrieval using a fractional Fourier system," Journal of the Optical Society of America A, vol. 25, no. 1, pp. 108-115, 2008.

[191] E. Lavely, Y. Zhang, E. Hill III, Y. Lai, P. Weichman, and A. Chapman, "Theoretical and experimental study of through-wall microwave tomography inverse problems," Journal of the Franklin Institute, vol. 345, no. 6, pp. 592-617, 2008.

[192] E. Li, Y. Liu, X. Liu, K. Zhang, Z. Wang, Y. Hong, Q. Yuan, W. Huang, A. Marcelli, P. Zhu, et al., "Phase retrieval from a single near-field diffraction pattern with a large Fresnel number," Journal of the Optical Society of America A, vol. 25, no. 11, pp. 2651-2658, 2008.

[193] L. Li, W. Zhang, and F. Li, "Tomographic reconstruction using the distorted Rytov iterative method with phaseless data," IEEE Geoscience and Remote Sensing Letters, vol. 5, no. 3, pp. 479-483, 2008.

[194] D. Montiel, M. Sutton, and M. Grant, "Phase retrieval by propagation for localized images," Journal of the Optical Society of America A, vol. 25, no. 11, pp. 2784-2790, 2008.

[195] N. Nakajima, "Lensless coherent imaging by a deterministic phase retrieval method with an aperture-array filter," Journal of the Optical Society of America A, vol. 25, no. 3, pp. 742-750, 2008.

[196] L. Paivarinta and J. Sylvester, "Transmission eigenvalues," SIAM J. Math. Anal, vol. 40, pp. 738-753, 2008.

[197] S. Razavi and Y. Rahmat-Samii, "Polarization Extraction in Planar Near-Field Phaseless Measurements," IEEE Transactions on Antennas and Propagation, vol. 56, no. 10, pp. 3233-3240, 2008.

[198] F. Soldovieri, R. Solimene, and R. Pierri, "Reconstructing the contour of metallic planar objects from only intensity scattered field data over a single plane," Optics Express, vol. 16, no. 13, pp. 9468-9479, 2008.

[199] T. Varslot et al., "Wide-band pulse-echo imaging with distributed apertures in multi-path environments," Inverse Problems, vol. 24, p. 045013,2008

[200] I. Al-Naib and K. Sayidmarie, "Prediction of channel parameters from amplitude-only data using Prony algorithm," Electronics letters, vol. 45 , p. 785, 2009.

[201] A. Capozzoli, C. Curcio, G. D’Elia, and A. Liseno, "Phaseless Antenna Characterization by Effective Aperture Field and Data Representations," IEEE Transactions on Antennas and Propagation, vol. 57, no. 1, pp. 215-230, 2009.

[202] J. Fridén, H. Isaksson, B. Hansson, and B. Thors, "Robust phaseretrieval for quick whole-body SAR assessment using dual plane amplitude-only data," Electronics Letters, vol. 45, p. 1155, 2009.

[203] U. Hasar, M. ERTUGRUL, and C. WESTGATE, "Noniterative permittivity extraction of lossy liquid materials from reflection asymmetric amplitude-only microwave measurements," IEEE microwave and wireless components letters, vol. 19, no. 6, pp. 419-421, 2009.

[204] G. Hislop, L. Li, and A. Hellicar, "Phase Retrieval for Millimeter-and Submillimeter-Wave Imaging," IEEE Transactions on Antennas and Propagation, vol. 57, no. 1, pp. 286-290, 2009.

[205] M. Langer, P. Cloetens, and F. Peyrin, "Fourier-wavelet regularization of phase retrieval in x-ray in-line phase tomography," Journal of the Optical Society of America A, vol. 26, no. 8, pp. 1876-1881, 2009.

[206] L. Li, H. Zheng, and F. Li, "Two-dimensional contrast source inversion method with phaseless data: TM case," IEEE Transactions on Geoscience and Remote Sensing, vol. 47, no. 6, pp. 1719-1736, 2009.

[207] Y. Li, J. Archer, J. Tello, G. Rosolen, F. Ceccato, S. Hay, A. Hellicar, and Y. Guo, "Performance Evaluation of a Passive Millimeter-Wave Imager," IEEE transactions on microwave theory and techniques, vol. 57, no. 10, pp. 2391-2405, 2009.

[208] N. Nakajima, "Phase retrieval from a high-numerical-aperture intensity distribution by use of an aperture-array filter," Journal of the Optical Society of America A, vol. 26, no. 10, pp. 2172-2180, 2009.

[209] D. Pliakis and S. Minardi, "Phase front retrieval by means of an iterative shadowgraphic method," Journal of the Optical Society of America A, vol. 26, no. 1, pp. 99-107, 2009.

[210] S. Thurman and J. Fienup, "Phase retrieval with signal bias," JOSA A, vol. 26, no. 4, pp. 1008-1014, 2009.

[211] J. Wilson and N. Patwari, "Radio tomographic imaging with wireless networks," IEEE Trans. Mobile Computing, 2009.

[212] W. Zhang, L. Li, and F. Li, "Multifrequency imaging from intensityonly data using the phaseless data distorted Rytov iterative method," IEEE Transactions on Antennas and Propagation, vol. 57, no. 1, pp. 290-295, 2009.
[213] Y. Xiang, L. Li, and F. Li, "A Novel Phase Retrieval Approach for Electromagnetic Inverse Scattering Problem with Intensity-Only Data," Progress In Electromagnetics Research, vol. 12, pp. 229-245, 2010.

[214] A. Capozzoli, C. Curcio, G. D’Elia, and A. Liseno, "Millimeter-wave phaseless antenna characterization," Language, vol. 18, p. 9456.

[215] C. Reeve and J. Wombwell, "Novel space-integrating acousto-optic correlator: amplitude and phase information from intensity only measurements,"

[216] T. Isernia, G. Leone, and R. Pierri, "Phaseless near field techniques: uniqueness conditions and attainment of the solution," Journal of electromagnetic waves and applications, vol. 8, no. 7, pp. 889-908, 1994.

[217] T. Isernia, G. Leone, and R. Pierri, "Phaseless near field techniques: formulation of the problem and field properties," Journal of electromagnetic waves and applications, vol. 8, no. 7, pp. 871-888, 1994.

[218] T. Isernia, G. Leone, and R. Pierri, "Numerical and experimental validation of a phaseless planar near field technique," Journal of Electromagnetic Waves and Applications, 9, vol. 1, no. 2, pp. 267284, 1995 .

[219] C. Chiu and P. Liu, "Image reconstruction of a perfectly conducting cylinder by thegenetic algorithm," IEE Proceedings-Microwaves, Antennas and Propagation, vol. 143, no. 3, pp. 249-253, 1996.

[220] A. Liseno, F. Tartaglione, and F. Soldovieri, "Shape reconstruction of 2-D buried objects under a Kirchhoff approximation," IEEE Geoscience and Remote Sensing Letters, vol. 1, no. 2, 2004.

[221] R. Pierri, R. Solimene, A. Liseno, and J. Romano, "Linear distribution imaging of thin metallic cylinders under mutual scattering," IEEE Transactions on Antennas and Propagation, vol. 53, no. 9, p. 3019, 2005.

[222] R. Pierri, A. Liseno, R. Solimene, and F. Soldovieri, "Beyond physical optics SVD shape reconstruction of metallic cylinders," IEEE Transactions on Antennas and Propagation, vol. 54, no. 2, p. 655, 2006.

[223] R. Wildman and D. Weile, "Geometry reconstruction of conducting cylinders using genetic programming," IEEE Transactions on Antennas and Propagation, vol. 55, no. 3 Part 1, pp. 629-636, 2007.

[224] F. Soldovieri and R. Pierri, "Shape reconstruction of metallic objects from intensity scattered field data only," Optics letters, vol. 33, no. 3, pp. 246-248, 2008.

[225] D. Woten, M. Hajihashemi, A. Hassan, and M. El-Shenawee, "Experimental Microwave Validation of Level Set Reconstruction Algorithm," IEEE transactions on antennas and propagation, vol. 58, no. 1, p. 231, 2010.

[226] G. Hislop, G. James, and A. Hellicar, "Phase retrieval of scattered fields," IEEE Transactions on Antennas and Propagation, vol. 55, no. 8, pp. 2332-2341, 2007.

[227] N. Guo, Q. Zhang, P. Zhang, Z. Hu, Y. Song, and R. C. Qiu, "UWB Real-Time Testbed with Waveform-Based Precoding," in IEEE MILCOM'08, (San Diego, CA), Nov. 2008

[228] N. Guo, R. C. Qiu, Q. Zhang, B. M. Sadler, Z. Hu, P. Zhang, Y. Song, and C. M. Zhou, Handbook of Sensor Networks, ch. Time Reversal for Ultra-Wideband Communications: Architecture and Test-bed, pp. 1-41. World Scientific Publishing, 2009.

[229] C. Prada and M. Fink, "Eigenmodes of the time reversal operator: A solution to selective focusing in multiple-target media," Wave motion, vol. 20, no. 2, pp. 151-163, 1994.

[230] D. Colton and R. Kress, "Eigenvalues of the far field operator for the Helmholtz equation in an absorbing medium," SIAM Journal on Applied Mathematics, pp. 1724-1735, 1995.

[231] C. Prada, J. Thomas, and M. Fink, "The iterative time reversal process: Analysis of the convergence," The Journal of the Acoustical Society of America, vol. 97, p. 62, 1995

[232] C. Prada, S. Manneville, D. Spoliansky, and M. Fink, "Decomposition of the time reversal operator: Detection and selective focusing on two scatterers," The Journal of the Acoustical Society of America, vol. 99, p. 2067, 1996.

[233] T. Mast, A. Nachman, and R. Waag, "Focusing and imaging using eigenfunctions of the scattering operator," The Journal of the Acoustical Society of America, vol. 102, p. 715, 1997.

[234] A. Kirsch, "Characterization of the shape of a scattering obstacle using the spectral data of the far field operator," Inverse problems, vol. 14, p. 1489,1998

[235] M. Lassas, M. Cheney, and G. Uhlmann, "Uniqueness for a wave propagation inverse problem in a half-space," Inverse Problems, vol. 14, p. 679, 1998. 
[236] R. Snieder and J. Scales, "Time-reversed imaging as a diagnostic of wave and particle chaos," Physical Review E, vol. 58, no. 5, pp. 5668$5675,1998$.

[237] N. Mordant, C. Prada, and M. Fink, "Highly resolved detection and selective focusing in a waveguide using the DORT method," The Journal of the Acoustical Society of America, vol. 105, p. 2634, 1999.

[238] A. Sengupta and P. Mitra, "Distributions of singular values for some random matrices," Physical Review E, vol. 60, no. 3, pp. 3389-3392, 1999

[239] H. Tortel, G. Micolau, and M. Saillard, "Decomposition of the time reversal operator for electromagnetic scattering," Journal of Electromagnetic Waves and Applications, vol. 13, no. 5, pp. 687-719, 1999.

[240] D. Chambers and A. Gautesen, "Time reversal for a single spherical scatterer," The Journal of the Acoustical Society of America, vol. 109 p. 2616,2001

[241] M. Cheney, "The linear sampling method and the MUSIC algorithm," Inverse Problems, vol. 17, p. 591, 2001.

[242] M. Fink and C. Prada, "Acoustic time-reversal mirrors," Inverse Problems, vol. 17, p. R1, 2001.

[243] I. Johnstone, "On the distribution of the largest eigenvalue in principal components analysis," Annals of Statistics, vol. 29, no. 2, pp. 295-327, 2001

[244] P. Blomgren, G. Papanicolaou, and H. Zhao, "Super-resolution in timereversal acoustics," The Journal of the Acoustical Society of America, vol. 111, p. 230, 2002.

[245] L. Borcea, G. Papanicolaou, C. Tsogka, and J. Berryman, "Imaging and time reversal in random media," Inverse Problems, vol. 18, p. 1247 2002

[246] D. Chambers, "Analysis of the time-reversal operator for scatterers of finite size," The Journal of the Acoustical Society of America, vol. 112, p. 411,2002

[247] M. Cheney, D. Isaacson, and M. Lassas, "Optimal acoustic measurements," Ultra-Wideband, Short-Pulse Electromagnetics 5, pp. 599-603 2002.

[248] E. Kerbrat and D. Prada, "Ultrasonic nondestructive testing of scattering media using the decomposition of the time-reversal operator," IEEE Transactions on Ultrasonics, Ferroelectrics, and Frequency Control, vol. 49, no. 8, p. 1103, 2002.

[249] A. Kirsch, "The MUSIC-algorithm and the factorization method in inverse scattering theory for inhomogeneous media," Inverse Problems, vol. 18, p. 1025, 2002.

[250] G. Bal and L. Ryzhik, "Time reversal and refocusing in random media," SIAM Journal on Applied Mathematics, vol. 63, no. 5, pp. 1475-1498, 2003.

[251] L. Borcea, G. Papanicolaou, and C. Tsogka, "Theory and applications of time reversal and interferometric imaging," Inverse Problems, vol. 19, p. S139, 2003.

[252] L. Carin and L. Couchman, "Time-Reversal Imaging of Distant Targets in a Shallow Water Channel," in OCEANS-CONFERENCE-, vol. 2, pp. 911-911, IEEE; 1998, 2003.

[253] A. Devaney and M. Dennison, "Inverse scattering in inhomogeneous background media," Inverse Problems, vol. 19, p. 855, 2003.

[254] S. Kim, W. Kuperman, W. Hodgkiss, H. Song, G. Edelmann, and T. Akal, "Robust time reversal focusing in the ocean," The Journal of the Acoustical Society of America, vol. 114, p. 145, 2003.

[255] S. Lehman and A. Devaney, "Transmission mode time-reversal superresolution imaging," The Journal of the Acoustical Society of America, vol. 113, p. 2742, 2003.

[256] G. Micolau and M. Saillard, "DORT method as applied to electromagnetic subsurface sensing," Radio Science, vol. 38, no. 3, p. 1038, 2003

[257] G. Micolau, M. Saillard, and P. Borderies, "DORT method as applied to ultrawideband signals for detection of buried objects," IEEE Transactions on geoscience and remote sensing, vol. 41, no. 8, pp. 1813-1820, 2003.

[258] G. Micolau, M. Saillard, and P. Borderies, "DORT method as applied to ultrawideband signals for detection of buried objects," IEEE Transactions on geoscience and remote sensing, vol. 41, no. 8, pp. 1813-1820, 2003

[259] C. Prada and J. Thomas, "Experimental subwavelength localization of scatterers by decomposition of the time reversal operator interpreted as a covariance matrix," The Journal of the Acoustical Society of America, vol. 114 , p. 235,2003
[260] G. Bal, "On the self-averaging of wave energy in random media," Multiscale Modeling \& Simulation, vol. 2, pp. 398-420, 2004.

[261] G. Bal and R. Verástegui, "Time reversal in changing environments,' Multiscale Modeling \& Simulation, vol. 2, p. 639, 2004.

[262] L. Carin, H. Liu, T. Yoder, L. Couchman, B. Houston, and J. Bucaro, "Wideband time-reversal imaging of an elastic target in an acoustic waveguide," The Journal of the Acoustical Society of America, vol. 115, p. 259,2004

[263] D. Chambers and J. Berryman, "Analysis of the time-reversal operator for a small spherical scatterer in an electromagnetic field," IEEE Transactions on Antennas and Propagation, vol. 52, no. 7, pp. 17291738, 2004.

[264] N. Dasgupta and L. Carin, "Time-reversal imaging and classification for distant targets in a shallow water channel," in ICASSP, 2004.

[265] A. Devaney, "Super-resolution processing of multi-static data using time reversal and MUSIC," J. Acoust. Soc. Am, 2004.

[266] F. Gruber, E. Marengo, and A. Devaney, "Time-reversal imaging with multiple signal classification considering multiple scattering between the targets," The Journal of the Acoustical Society of America, vol. 115, p. 3042, 2004

[267] S. Hou, K. Solna, and H. Zhao, "Imaging of location and geometry for extended targets using the response matrix," Journal of Computational Physics, vol. 199, no. 1, pp. 317-338, 2004.

[268] O. Ledoit and M. Wolf, "A well-conditioned estimator for largedimensional covariance matrices," Journal of multivariate analysis, vol. 88 , no. 2 , pp. $365-411,2004$.

[269] H. Zhao, "Analysis of the response matrix for an extended target," SIAM Journal on Applied Mathematics, vol. 64, no. 3, pp. 725-745, 2004.

[270] A. Devaney, E. Marengo, and M. Li, "Inverse problem in inhomogeneous background media: Multiple-frequency case and SVD formulation," Inverse Problems, vol. 20, no. 5, pp. 1307-1324, 2004.

[271] H. Ammari, E. Iakovleva, and D. Lesselier, "A MUSIC algorithm for locating small inclusions buried in a half-space from the scattering amplitude at a fixed frequency," Multiscale Modeling and Simulation, vol. 3, no. 3, p. 597, 2005.

[272] A. Devaney, "Time reversal imaging of obscured targets from multistatic data," IEEE Transactions on Antennas and Propagation, vol. 53 , no. 5, 2005.

[273] A. Devaney, E. Marengo, and F. Gruber, "Time-reversal-based imaging and inverse scattering of multiply scattering point targets," The Journal of the Acoustical Society of America, vol. 118, p. 3129, 2005.

[274] A. Fannjiang and K. Solna, "Propagation and time reversal of wave beams in atmospheric turbulence," Multiscale Modeling and Simulation, vol. 3, no. 3, p. 522, 2005.

[275] D. Liu, G. Kang, L. Li, Y. Chen, S. Vasudevan, W. Joines, Q. Liu, J. Krolik, and L. Carin, "Electromagnetic time-reversal imaging of a target in a cluttered environment," IEEE Transactions on Antennas and Propagation, vol. 53, no. 9, 2005.

[276] J. Minonzio, C. Prada, D. Chambers, D. Clorennec, and M. Fink, "Characterization of subwavelength elastic cylinders with the decomposition of the time-reversal operator: Theory and experiment," The Journal of the Acoustical Society of America, vol. 117, p. 789, 2005.

[277] D. Chambers and J. Berryman, "Target characterization using decomposition of the time-reversal operator: electromagnetic scattering from small ellipsoids," Inverse Problems, vol. 22, p. 2145, 2006.

[278] S. Hou, K. Solna, and H. Zhao, "A direct imaging algorithm for extended targets," Inverse Problems, vol. 22, p. 1151, 2006.

[279] C. Johan and E. Marengo, "Inverse source problem in an oblate spheroidal geometry," IEEE Transactions on Antennas and Propagation, vol. 54, no. 11, 2006.

[280] E. Marengo and F. Gruber, "Noniterative analytical formula for inverse scattering of multiply scattering point targets," The Journal of the Acoustical Society of America, vol. 120, p. 3782, 2006.

[281] J. Robert, M. Burcher, C. Cohen-Bacrie, and M. Fink, "Time reversal operator decomposition with focused transmission and robustness to speckle noise: Application to microcalcification detection," The Journal of the Acoustical Society of America, vol. 119, p. 3848, 2006.

[282] M. Yavuz and F. Teixeira, "Full time-domain DORT for ultrawideband electromagnetic fields in dispersive, random inhomogeneous media," IEEE Transactions on Antennas and Propagation, vol. 54, no. 8, pp. 2305-2315, 2006.

[283] H. Ammari, E. Iakovleva, D. Lesselier, and G. Perrusson, "MUSICtype electromagnetic imaging of a collection of small three-dimensional 
bounded inclusions," SIAM J. Sci. Comput.(USA), vol. 29, pp. 674-709, 2007

[284] D. Chambers, "Target characterization using time-reversal symmetry of wave propagation," International Journal of Modern Physics B, vol. 21, no. 20, pp. 3511-3555, 2007.

[285] G. Derveaux, G. Papanicolaou, and C. Tsogka, "Time reversal imaging for sensor networks with optimal compensation in time," The Journal of the Acoustical Society of America, vol. 121, p. 2071, 2007.

[286] A. Devaney, E. Marengo, and M. A. Li, "Inverse source problem in nonhomogeneous background media," SIAM Journal on Applied Mathematics, vol. 67, no. 5, pp. 1353-1378, 2007.

[287] G. Edelmann, J. Lingevitch, C. Gaumond, D. Fromm, and D. Calvo, "Comparison of a subrank to a full-rank time-reversal operator in a dynamic ocean," The Journal of the Acoustical Society of America, vol. 122, p. 2706, 2007.

[288] S. Hou, K. Solna, and H. Zhao, "A direct imaging method using farfield data," Inverse Problems, vol. 23, p. 1533, 2007.

[289] E. Iakovleva, S. Gdoura, D. Lesselier, and G. Perrusson, "Multistatic response matrix of a 3-D inclusion in half space and MUSIC imaging," IEEE Transactions on Antennas and Propagation, vol. 55, no. 9, pp. 2598-2609, 2007.

[290] D. Liu, J. Krolik, and L. Carin, "Electromagnetic target detection in uncertain media: Time-reversal and minimum-variance algorithms," IEEE Transactions on Geoscience and Remote Sensing, vol. 45, no. 4, pp. 934-944, 2007.

[291] D. Liu, S. Vasudevan, J. Krolik, G. Bal, and L. Carin, "Electromagnetic time-reversal source localization in changing media: Experiment and analysis," IEEE Transactions on Antennas and Propagation, vol. 55, no. 2, pp. 344-354, 2007.

[292] E. Marengo and F. Gruber, "Subspace-based localization and inverse scattering of multiply scattering point targets," EURASIP Journal on Applied Signal Processing, vol. 2007, no. 1, p. 192, 2007.

[293] E. Marengo, F. Gruber, and F. Simonetti, "Time-reversal MUSIC imaging of extended targets," IEEE Transactions on Image Processing, vol. 16 , no. 8, pp. 1967-1984, 2007.

[294] Z. Bai, "Methodologies in spectral analysis of large dimensional random matrices, a review," in Advances in statistics: proceedings of the conference in honor of Professor Zhidong Bai on his 65th birthday, National University of Singapore, 20 July 2008, vol. 9, p. 174, World Scientific Pub Co Inc, 2008.

[295] L. Carin, D. Liu, and B. Guo, "In situ compressive sensing," Inverse Problems, vol. 24, p. 015023, 2008.

[296] A. Devaney, G. Kaiser, E. Marengo, R. Albanese, and G. Erdmann, "The inverse source problem for wavelet fields," IEEE Transactions on Antennas and Propagation, vol. 56, no. 10, pp. 3179-3187, 2008.

[297] N. El Karoui, "Spectrum estimation for large dimensional covariance matrices using random matrix theory," The Annals of Statistics, vol. 36, no. 6 , pp. $2757-2790,2008$

[298] F. Gruber and E. Marengo, "New Aspects of Electromagnetic Information Theory for Wireless and Antenna Systems," IEEE Transactions on Antennas and Propagation, vol. 56, no. 11, pp. 3470-3484, 2008.

[299] F. Gruber and E. Marengo, "New Aspects of Electromagnetic Information Theory for Wireless and Antenna Systems," IEEE Transactions on Antennas and Propagation, vol. 56, no. 11, pp. 3470-3484, 2008.

[300] E. Iakovleva and D. Lesselier, "Multistatic response matrix of spherical scatterers and the back-propagation of singular fields," IEEE Transactions on Antennas and Propagation, vol. 56, no. 3, p. 825, 2008.

[301] C. Johan and E. Marengo, "Inverse source problem in the spheroidal geometry: Vector formulation," IEEE Transactions on Antennas and Propagation, vol. 56, no. 4, p. 961, 2008.

[302] J. Li, H. Zhao, and W. Fang, "Experimental investigation of selective localisation by decomposition of the time reversal operator and subspace-based technique," 2008.

[303] E. Marengo, M. Khodja, and A. Boucherif, "Inverse source problem in non-homogeneous background media. Part II: Vector formulation and antenna substrate performance characterization," SIAM J. Appl. Math, vol. 69 , no. 1 , pp. $81-110,2008$.

[304] J. Minonzio, F. Philippe, C. Prada, and M. Fink, "Characterization of an elastic cylinder and an elastic sphere with the time-reversal operator: application to the sub-resolution limit," Inverse Problems, vol. 24, p. 025014, 2008.

[305] F. Simonetti, M. Fleming, and E. Marengo, "Illustration of the role of multiple scattering in subwavelength imaging from far-field measurements," JOSA A, vol. 25, no. 2, pp. 292-303, 2008.
[306] M. Yavuz and F. Teixeira, "On the sensitivity of time-reversal imaging techniques to model perturbations," IEEE transactions on antennas and propagation, vol. 56, no. 3, pp. 834-843, 2008.

[307] M. Yavuz and F. Teixeira, "Space-frequency ultrawideband timereversal imaging," IEEE Transactions on Geoscience and Remote Sensing, vol. 46, no. 4, p. 1115, 2008.

[308] Y. Ziadé, H. Roussel, M. Lesturgie, and W. Tabbara, "A Coherent Model of Forest Propagation: Application to Detection and Localization of Targets Using the DORT Method," IEEE transactions on antennas and propagation, vol. 56, no. 4, pp. 1048-1057, 2008.

[309] H. Ammari, H. Kang, H. Lee, and W. Park, "Asymptotic imaging of perfectly conducting cracks," SIAM J. Sci. Comput, 2009.

[310] A. Aubry and A. Derode, "Random Matrix Theory Applied to Acoustic Backscattering and Imaging In Complex Media," Physical review letters, vol. 102, no. 8, p. 84301, 2009

[311] S. Hou, K. Huang, K. Solna, and H. Zhao, "A phase and space coherent direct imaging method," The Journal of the Acoustical Society of America, vol. 125, p. 227, 2009.

[312] J. Minonzio, M. Davy, J. de Rosny, C. Prada, and M. Fink, "Theory of the Time-Reversal Operator for a Dielectric Cylinder Using Separate Transmit and Receive Arrays," IEEE transactions on antennas and propagation, vol. 57, no. 8, pp. 2331-2340, 2009.

[313] A. Aubry and A. Derode, "Detection and imaging in a random medium: a matrix method to overcome multiple scattering and aberration," $J$. Appl. Phys., vol. 106, pp. 044903-1, 2009.

[314] A. Aubry and A. Derode, "Singular value distribution of the propagation matrix in random scattering media," Waves in Random and Complex Media, vol. 99999, no. 1, pp. 1-31, 2010.

[315] M. Davy, J. Minonzio, J. de Rosny, C. Prada, and M. Fink, "Experimental Study of the Invariants of the Time-Reversal Operator for a Dielectric Cylinder Using Separate Transmit and Receive Arrays,' IEEE Transactions on Antennas and Propagation, vol. 58, no. 4, p. 1349,2010

[316] F. Gruber and E. Marengo, "Inverse scattering of extended targets by signal subspace approaches and the level set method," Citeseer.

[317] F. Gruber and E. Marengo, "Reinterpretation and Enhancement Of Signal-Subspace-Based Imaging Methods For Extended Scatterers,"

[318] S. HOU, K. SOLNA, and H. ZHAO, "Detection and imaging in a strongly cluttered environment," http://www.math.uci.edu/ zhao/publication/mypapers/pdf/clutter.pdf.

[319] H. Lev-Ari and A. Devaney, "The time-reversal technique reinterpreted: Subspace-based signal processing for multi-static target location," in Proceedings of the 2000 IEEE Sensor Array and Multichannel Signal Processing Workshop (IEEE, 2000), pp. 509-513.

[320] H. Liu, N. Dasgupta, and L. Carin, "Time-reversal imaging for wideband underwater target classification," in Acoustics, Speech, and Signal Processing, 2003. Proceedings.(ICASSP03). 2003 IEEE International Conference on, vol. 5, pp. 5-8.

[321] D. Nguyen, W. Gan, and Y. Chong, "Detection and localization of the scatterers via DORT method," dimension, vol. 500, no. 11, p. 1 .

[322] R. Qiu and P. Zhang, "Blind Spectrum Sensing Based on Feature Extraction." US Patent, Pending.

[323] M. Wicks and W. Moore, "Distributed and Layered Sensing," in Waveform Diversity and Design Conference, 2007. International, pp. 233239, 2007

[324] M. Armbrust, A. Fox, R. Griffith, A. Joseph, R. Katz, A. Konwinski, G. Lee, D. Patterson, A. Rabkin, I. Stoica, et al., "Above the clouds: A berkeley view of cloud computing," EECS Department, University of California, Berkeley, Tech. Rep. UCB/EECS-2009-28, 2009.

[325] R. Mueller, M. Kaveh, and G. Wade, "Reconstructive tomography and applications to ultrasonics," in Proc. IEEE, Volume 67, p. 567-587, vol. 67 , pp. $567-587,1979$.

[326] A. Devaney, "Maximum likelihood estimation of object location in diffraction tomography," IEEE Transactions on Signal Processing, vol. 39 , no. 3, 1991.

[327] G. Tsihrintzis, "Maximum likelihood estimation of object location in diffraction tomography. II. Strongly scattering objects," IEEE Transactions on Signal Processing, vol. 39, no. 6, pp. 1466-1470, 1991.

[328] G. Tsihrintzis, A. Devaney, and E. Heyman, "Estimation of object location from wideband scattering data," IEEE Transactions on Image Processing, vol. 8, no. 7, pp. 996-1001, 1999.

[329] G. Tsihrintzis, A. Devaney, and E. Heyman, "Estimation of object location from short pulse scatter data," in Proceedings of SPIE, vol. 3392 , p. 918,1998 
[330] G. Tsihrintzis, "Estimation of object location from diffraction tomographic intensity data," IEEE Transactions on Signal Processing, vol. 39, no. 9, pp. 2136-2140, 1991. 